\title{
Safety and Effectiveness of Biphasic Insulin Aspart 30 in Different Age-Groups: $A_{1}$ chieve Sub-Analysis
}

\author{
Mohammad Ebrahim Khamseh • Jihad Haddad • \\ Wenying Yang • Alexey Zilov • Ole Molskov Bech • \\ Mohammad Imtiaz Hasan
}

To view enhanced content go to www.diabetestherapy-open.com

Received: April 10, 2013 / Published online: July 17, 2013

(C) The Author(s) 2013. This article is published with open access at Springerlink.com

\section{ABSTRACT}

Introduction: Effective management of type 2 diabetes requires sustained glycemic control over many years, which can be particularly challenging for elderly people. This sub-analysis of the $A_{1}$ chieve study evaluated the clinical safety and effectiveness of biphasic insulin aspart 30 in 3 age-groups $(\leq 40,>40-65$, and $>65$ years) of previously insulin-experienced and insulin-naïve people with type 2 diabetes.

This trial was registered with ClinicalTrials.gov (NCT00869908).

M. E. Khamseh

Endocrine Research Centre (Firouzgar), Institute of Endocrinology and Metabolism, Tehran University of Medical Sciences, Tehran, Iran

J. Haddad

Endocrinology Section, Department of Internal Medicine, Prince Hamzah Hospital, Amman, Jordan
Methods: $\mathrm{A}_{1}$ chieve was an international, multicenter, prospective, open-label, noninterventional, 24-week study in people with type 2 diabetes who had been receiving antidiabetes medication before starting, or switching to, therapy with biphasic insulin aspart 30, insulin detemir or insulin aspart (alone or in combination) in routine clinical practice. This sub-analysis evaluated clinical safety and effectiveness of biphasic insulin aspart 30 ( \pm oral glucose-lowering drugs) in different age-groups.

Results: Data on 40,122 participants were included. In all age-groups, the proportion of

W. Yang

China-Japan Friendship Hospital, Beijing, China

\section{A. Zilov}

Department of Endocrinology, First Moscow State Medical University, Moscow, Russia

O. M. Bech ( $\square)$

Novo Nordisk Saglik Ürünleri Tic. Ltd. Sti., Istanbul, Turkey

e-mail: omb@novonordisk.com

M. I. Hasan

Diabetics' Institute Pakistan, Lahore, Pakistan 
participants experiencing any hypoglycemia, major hypoglycemia or nocturnal hypoglycemia was significantly reduced from baseline, except for the following in insulin-naïve patients: a significant increase in any hypoglycemia in patients aged >65 years; no change in any hypoglycemia, major hypoglycemia, and nocturnal hypoglycemia in patients aged $>40-65, \leq 40$, and >65 years, respectively. Significant improvements at 24 weeks vs. baseline were observed in insulin-experienced and insulin-naïve participants for: glycated hemoglobin (change from baseline ranged from $-1.8 \%$ to $-2.4 \%$ ); fasting plasma glucose (from 3.0 to $-4.3 \mathrm{mmol} / \mathrm{l})$; post-breakfast post-prandial plasma glucose (from -4.1 to $-6.5 \mathrm{mmol} / \mathrm{l}$ ); and health-related quality of life (HRQoL). Sixteen serious adverse drug reactions were reported.

Conclusion: After 24-week treatment with biphasic insulin aspart 30, all age-groups of insulin-experienced and insulin-naïve patients experienced significantly improved glycemic control and HRQoL; incidence of hypoglycemia was generally reduced. The tolerability and effectiveness of biphasic insulin aspart 30 may benefit all age-groups.

Keywords: Biphasic insulin aspart; Noninterventional study; Observational study; Type 2 diabetes

\section{INTRODUCTION}

Worldwide, an estimated 366 million people had diabetes in 2011 and the number is expected to grow to 552 million by 2030 [1]. The 2005-2006 National Health and Nutrition Examination Survey of community-dwelling adults showed that the prevalence of diabetes increases with age, peaking at 60-74 years of age (crude prevalence 17.6\%) [2].
Effective management of diabetes requires sustained glycemic control over many years. This can be a challenge for all patients with diabetes, but particularly in elderly people with type 2 diabetes, due to co-morbidities and polypharmacy, among other issues. Furthermore, elderly patients may find it difficult to adequately self-monitor blood sugar levels due to poor dexterity, and cognitive and visual impairments, and may have impaired awareness of hypoglycemia compared with younger patients [3, 4]. Consequently, elderly people with type 2 diabetes have a higher rate of severe hypoglycemia than younger people with type 2 diabetes $[5,6]$.

Insulin analogs were developed to help people with diabetes improve their glycemic control and to address concerns over insulin therapy, particularly hypoglycemia and weight gain [7, 8]. Randomized controlled trials (RCTs) and non-interventional studies [9-16] have shown that a change of therapy from oral glucose-lowering drugs (OGLDs) or conventional insulin preparations to insulin analogs can be associated with clinically significant improvements in effectiveness measures and tolerability.

For many patients, biphasic insulin formulations offer a simple-to-use insulin regimen [17], providing greater lifestyle flexibility for the patient; they also offer the advantage of controlling both fasting plasma glucose (FPG) and post-prandial glucose (PPG) $[18,19]$. Biphasic insulin aspart 30 (NovoMix $^{\circledR}$ 30; Novo Nordisk A/S, Bagsvaerd, Denmark) may lead to improved PPG control compared with other insulin therapies, including premixed biosynthetic human insulin 30, and biphasic insulin lispro [20]. Furthermore, initiating insulin therapy with once- or twice-daily biphasic insulin aspart 30 (in people with type 2 
diabetes on various OGLD regimens) effectively controls glycated hemoglobin $\left(\mathrm{HbA}_{1 \mathrm{c}}\right)$ levels [18, 19]. Indeed, one study showed that significantly more insulin-naïve people with type 2 diabetes randomized to twice-daily biphasic insulin aspart 30 achieved $\mathrm{HbA}_{1 \mathrm{c}}<7.0 \%$ than those randomized to once-daily insulin glargine, especially among people with baseline $\mathrm{HbA}_{1 \mathrm{c}}$ $>8.5 \%$ [19]. Non-inferiority of once-daily biphasic insulin aspart 30 to once-daily insulin glargine has also been shown in people with type 2 diabetes inadequately controlled with OGLDs [21]. The effectiveness of biphasic insulin aspart 30 seen in short-term studies is maintained with long-term use $[22,23]$.

$A_{1}$ chieve was an international noninterventional study evaluating the safety and clinical effectiveness of insulin analogs in people with type 2 diabetes receiving routine clinical care in 28 countries across 4 continents. Given that different age-groups can respond differently to drug therapies, and have differing needs, this sub-analysis assessed the outcomes with biphasic insulin aspart 30 ( \pm OGLDs) in 3 age-groups ( $\leq 40,>40-65$ and $>65$ years) in the $\mathrm{A}_{1}$ chieve study, with and without previous experience of using insulin.

\section{MATERIALS AND METHODS}

$A_{1}$ chieve was an international prospective, multicenter, open-label, non-interventional, 24-week study in people with type 2 diabetes mellitus who had been using anti-diabetes medication before starting, or switching to, insulin therapy with biphasic insulin aspart 30, insulin aspart $\left(\right.$ NovoRapid $^{\circledR}$; Novo Nordisk A/S, Bagsvaerd, Denmark) or insulin detemir (Levemir $^{\circledR}$; Novo Nordisk A/S, Bagsvaerd, Denmark) with or without OGLDs in routine clinical practice [24]. The study was conducted in 28 countries, representing 7 geographical regions:
China; South Asia (Bangladesh, India, Pakistan); East Asia (Indonesia, Korea, Malaysia, Philippines, Singapore, Taiwan); North Africa (Algeria, Morocco, Tunisia, Libya); Middle East/Gulf (Egypt, Iran, Jordan, Turkey, Bahrain, Kuwait, Oman, Qatar, Saudi Arabia, United Arab Emirates, Yemen); Latin America (Argentina, Mexico); and Russia. Participants were patients attending a general practitioner or specialist who prescribed insulin analogs in their routine practice; participants were enrolled in the study between January 2009 and June 2010. Further details on inclusion and exclusion criteria, and study design have previously been reported [24].

Insulin analogs were used in the study in accordance with the label approved by the regulatory authority (all manufactured by Novo Nordisk A/S, Bagsvaerd, Denmark), and all local requirements for Health Authorities or Ethics Committee approvals were obtained, if applicable. In every country, participants signed informed consent forms and were free to withdraw from the study at any time. The study was conducted in accordance with the Declaration of Helsinki of 1964, as revised in 2008 [25] and guidelines for good pharmacoepidemiology practice [26].

\section{Assessments and Outcome Measures}

Trial visits were defined as baseline, interim [around 12 weeks from baseline (results not reported here)], and final visit (around 24 weeks from baseline). The amount of starting insulin and the amount of insulin administered at subsequent visits were recorded.

The primary objective was to evaluate the safety profile of insulin analogs by measuring the incidence of serious adverse drug reactions (SADRs), including major hypoglycemia events. Other safety assessments included the change in the number of hypoglycemia events (overall, 
major, nocturnal) between baseline and 24 weeks. These were based on patient recall of events within the 4 weeks preceding each study visit.

A hypoglycemia event was defined as an event with symptoms of hypoglycemia that resolved with oral carbohydrate intake, glucagon or intravenous glucose, or any symptomatic or asymptomatic event where plasma glucose was $<3.1 \mathrm{mmol} / \mathrm{l}$ or $56 \mathrm{mg} / \mathrm{dl}$. Major hypoglycemia events were defined as events with severe central nervous system symptoms consistent with hypoglycemia in which the patient was unable to self-treat and had one of the following characteristics: plasma glucose $<3.1 \mathrm{mmol} / \mathrm{l}$, or reversal of symptoms after either food intake, glucagon or intravenous glucose administration. Nocturnal hypoglycemia events were defined as individualized symptomatic events consistent with hypoglycemia between bedtime after the evening insulin injection and before getting up in the morning; if applicable, events were those that occurred before morning determination of FPG and the morning insulin injection.

Effectiveness measurements were secondary endpoints, and included the change in $\mathrm{HbA}_{1 \mathrm{c}}$, FPG levels before breakfast, PPG levels after breakfast, body weight, and health-related quality of life (HRQoL) between baseline and 24 weeks.

HRQoL was assessed at baseline and after 24 weeks by self-reporting using the EQ-5D questionnaire [27], which evaluates five domains of patient health/lifestyle (mobility, self-care, usual activities, pain/discomfort, and anxiety/ depression). Patient responses were evaluated on a visual analog scale (VAS) of 0 (worst imaginable health) to 100 (best imaginable health).

\section{Statistical Analysis}

This publication reports the results for patients who were administered biphasic insulin aspart
30 ( \pm OGLDs) in the $A_{1}$ chieve study. Analysis of each of the safety and effectiveness outcome measures was performed by age-group $(\leq 40$, $>40-65$, and $>65$ years) and pre-study insulin experience (insulin-experienced and insulinnaïve) for those receiving biphasic insulin aspart 30 ( \pm OGLDs). The age-groups were arbitrarily selected. All analyses were performed on the full analysis set, which was defined as all patients with a baseline visit and who used study insulin at least once. For hypoglycemia, the percentage of participants reporting at least one event was analyzed using McNemar's test. The number of SADRs deemed to be related to study insulin was also reported. Change from baseline data in effectiveness measures were analyzed using paired $t$ test. All data were analyzed by Novo Nordisk A/S using SAS $^{\circledR}$ Version 9.1.3 (SAS $^{\circledR}$ Institute Inc., Cary, NC, USA). The statistical significance level employed was $\alpha=0.05$ (two tailed). Missing data were not imputed. The sample size was based on the number of people $(20,000)$ exposed for 6 months required to confirm at $95 \%$ confidence a frequency of any one adverse drug reaction of $\geq 15$ events/100,000 personyears.

\section{RESULTS}

\section{Study Participants}

Of the total $A_{1}$ chieve study population, 40,122 people with type 2 diabetes received treatment with biphasic insulin aspart 30 ( \pm OGLDs). This included 4,347 people aged $\leq 40$ years, 29,036 people aged $>40-65$ years, and 6,739 people aged >65 years (Table 1 ). Due to the noninterventional nature of the study, some baseline data were missing and some patients were missing to follow-up. Most study 
Table 1 Baseline patient and disease characteristics by age-group

\begin{tabular}{|c|c|c|c|}
\hline & $\leq 40$ years & $>40-65$ years & $>65$ years \\
\hline Entire cohort, $n$ & 4,347 & 29,036 & 6,739 \\
\hline \multicolumn{4}{|l|}{ Insulin status } \\
\hline Insulin-experienced, $n(\%)$ & $1,109(25.5)$ & $8,998(31.0)$ & $2,943(43.7)$ \\
\hline Insulin-naïve, $n(\%)$ & $3,238(74.5)$ & $20,038(69.0)$ & $3,796(56.3)$ \\
\hline Mean (SD) age (years) & $33.3(8.5)$ & $53.1(6.5)$ & $71.3(5.0)$ \\
\hline Male, $n(\%)^{a}$ & $2,663(61.3)$ & $16,463(56.8)$ & $3,333(49.5)$ \\
\hline Mean $(\mathrm{SD})$ weight $(\mathrm{kg})^{\mathrm{b}}$ & $71.0(14.0)$ & $72.0(13.8)$ & $69.1(13.8)$ \\
\hline Mean $(\mathrm{SD})$ BMI $\left(\mathrm{kg} / \mathrm{m}^{2}\right)^{\mathrm{c}}$ & $25.8(4.4)$ & $26.8(4.6)$ & $26.3(4.8)$ \\
\hline Mean (SD) diabetes duration (years) ${ }^{\mathrm{d}}$ & $3.9(3.7)$ & $7.3(5.3)$ & $11.4(8.0)$ \\
\hline
\end{tabular}

Due to the non-interventional nature of this study, not all baseline data were recorded and some patients were lost to follow-up $B M I$ body mass index

a $n=4,342, n=29,008$ and $n=6,739$ for the $\leq 40$ years, $>40-65$ years and $>65$ years age-groups, respectively

b $n=4,161, n=27,744$, and $n=6,361$ for the $\leq 40$ years, $>40-65$ years and $>65$ years age-groups, respectively

c $n=3,916, n=25,885$, and $n=5,892$ for the $\leq 40$ years, $>40-65$ years and $>65$ years age-groups, respectively

d $n=4,109, n=28,815$ and $n=6,673$ for the $\leq 40$ years, $>40-65$ years and $>65$ years age-groups, respectively

participants (67\%) were insulin-naïve before the study. The $>65$ years age-group had the longest diabetes duration (Table 1).

\section{Exposure}

The difference between the starting insulin dose and the insulin dose at 24 weeks in any agegroup was small. In the $\leq 40$ years age-group, the starting mean (SD) total insulin dose was 0.46 $(0.21) \mathrm{U} / \mathrm{kg}(n=4,161)$ and at 24 weeks was 0.50 $(0.25) \mathrm{U} / \mathrm{kg}(n=3,203)$. In the $>40-65$ years agegroup, the starting total insulin dose was 0.46 $(0.20) \mathrm{U} / \mathrm{kg}(n=27,738)$ and at 24 weeks was $0.51(0.24) \mathrm{U} / \mathrm{kg}(n=22,004)$. In the $>65$ years age-group, starting total insulin dose was 0.47 $(0.21) \mathrm{U} / \mathrm{kg}(n=6,361)$ and at 24 weeks was 0.52 (0.23) $\mathrm{U} / \mathrm{kg}(n=4,964)$.

This pattern was repeated in the insulinnaïve and insulin-experienced subgroups: insulin-naïve patients, $0.42 \mathrm{U} / \mathrm{kg}$ at baseline
( $\leq 40$ years: $n=3,123$; $>40-65$ years: $n=19,188$; $>65$ years: $n=3,613)$ and $0.46-0.47 \mathrm{U} / \mathrm{kg}$ after 24 weeks ( $\leq 40$ years: $n=2,447 ;>40-65$ years: $n=15,148$; $>65$ years: $n=2,778$ ) in the 3 agegroups; insulin-experienced patients, $0.54-0.59 \mathrm{U} / \mathrm{kg}$ at baseline ( $\leq 40$ years: $n=1,038$; >40-65 years: $n=8,550$; >65 years: $n=2,748)$ and $0.59-0.64 \mathrm{U} / \mathrm{kg}$ at 24 weeks ( $\leq 40$ years: $n=756$; $>40-65$ years: $n=6,856$; $>65$ years: $n=2,186)$ in the 3 age-groups.

The number of concomitant OGLDs used remained stable during the course of the 24 weeks of biphasic insulin aspart 30 therapy (Table 2); although the $>65$ years age-group tended to be receiving less OGLDs at 24 weeks than the $\leq 40$ and $>40-65$ years age-groups, there was no major difference in OGLD use between the age-groups (Table 2). Metformin and/or sulfonylureas were the predominant OGLDs in all age-groups at study initiation and after 24 weeks of treatment with biphasic 
Table 2 Number of OGLDs taken at baseline and following 24 weeks of therapy with biphasic insulin aspart 30

\begin{tabular}{|c|c|c|c|c|c|c|}
\hline \multirow[t]{2}{*}{ Number of OGLDs } & \multicolumn{2}{|l|}{$\leq 40$ years } & \multicolumn{2}{|l|}{$>40-65$ years } & \multicolumn{2}{|l|}{$>65$ years } \\
\hline & Baseline & 24 weeks & Baseline & 24 weeks & Baseline & 24 weeks \\
\hline All, $n$ & 4,347 & 3,620 & 29,036 & 25,134 & 6,739 & 5,688 \\
\hline No OGLDs, $n$ (\% of cohort) & $1,629(37.5)$ & $1,166(32.2)$ & $8,421(29.0)$ & $6,489(25.8)$ & $2,815(41.8)$ & $2,256(39.7)$ \\
\hline One OGLD, $n$ (\% of cohort) & $1,654(38.0)$ & $1,388(38.3)$ & $13,000(44.8)$ & $11,240(44.7)$ & $2,677(39.7)$ & $2,420(42.5)$ \\
\hline$\geq$ Two OGLDs, $n$ (\% of cohort) & $1,064(24.5)$ & $1,066(29.4)$ & $7,615(26.2)$ & $7,405(29.5)$ & $1,247(18.5)$ & $1,012(17.8)$ \\
\hline
\end{tabular}

Due to the non-interventional nature of this study, not all baseline data were recorded and some patients were lost to follow-up

OGLDs oral glucose-lowering drugs

insulin aspart 30 ; $>70 \%$ of patients in all agegroups were prescribed metformin after 24 weeks.

\section{Safety Measures}

\section{All Hypoglycemia Events}

After 24 weeks, the proportion of participants experiencing hypoglycemia events in the entire cohort decreased significantly from baseline in all age-groups (all $p<0.01$; Table 3). This pattern was also seen among insulin-experienced participants (all $p<0.001$; Table 3). As with the insulin-experienced group, there was a significant reduction in the proportion of insulin-naïve participants experiencing hypoglycemia in the $\leq 40$ years age-group $(p<0.05)$; however, there was no statistically significant change in the $>40-65$ years age-group and a significant increase in the $>65$ years age-group $(p<0.001$; Table 3). There did not appear to be a trend between the length of time in years from diagnosis of diabetes and total hypoglycemia events (results not shown). Neither did there seem to be an association between sulfonylurea use and the total number of hypoglycemia events (Table 3).

\section{Major Hypoglycemia Events}

The proportions of participants experiencing major hypoglycemia in the entire cohort and in insulin-experienced patients decreased significantly from baseline in all age-groups following 24 weeks' therapy with biphasic insulin aspart 30 (all $p<0.001$; Table 3). In insulin-naïve patients, there were significant reductions from baseline in the proportion of participants experiencing major hypoglycemia in the $>40-65$ years and $>65$ years age-groups (both $p<0.001$; Table 3), but no significant difference from baseline in the $\leq 40$ years agegroup.

\section{Nocturnal Hypoglycemia Events}

The proportions of participants experiencing nocturnal hypoglycemia in the entire cohort and in insulin-experienced patients decreased significantly from baseline in all age-groups following 24 weeks' therapy with biphasic insulin aspart 30 (all $p<0.001$; Table 3). The proportion of insulin-naïve patients experiencing nocturnal hypoglycemia was significantly reduced in the $\leq 40$ and $>40-65$ years age-groups at 24 weeks (both $p<0.001)$, with no significant change reported in the $>65$ years age-group (Table 3 ). 
Table 3 Safety outcomes before and after 24 weeks of treatment with biphasic insulin aspart 30 by age-group

\begin{tabular}{|c|c|c|c|c|c|c|}
\hline \multirow[t]{2}{*}{ Measurement } & \multicolumn{2}{|l|}{$\leq 40$ years } & \multicolumn{2}{|c|}{$>40-65$ years } & \multicolumn{2}{|l|}{$>65$ years } \\
\hline & Baseline & 24 weeks & Baseline & 24 weeks & Baseline & 24 weeks \\
\hline \multicolumn{7}{|c|}{ Overall hypoglycemia, \% patients with at least one event (event/person-year) } \\
\hline Entire cohort & $7.3(2.27)$ & $4.4^{* * *}(1.06)$ & $7.3(2.26)$ & $5.4^{* * *}(1.39)$ & $9.2(3.17)$ & $7.9^{* *}(2.11)$ \\
\hline$n$ & 4,347 & 3,620 & 29,036 & 25,134 & 6,739 & 5,688 \\
\hline Insulin-experienced & $16.2(6.54)$ & $8.9^{* * *}(2.19)$ & $14.9(5.15)$ & $8.3^{* * *}(2.22)$ & $16.2(5.99)$ & $10.3^{* * *}(2.90)$ \\
\hline$n$ & 1,109 & 868 & 8,998 & 7,712 & 2,943 & 2,502 \\
\hline Insulin-naïve & $4.2(0.80)$ & $3.0^{*}(0.71)$ & $3.9(0.96)$ & $4.1(1.02)$ & $3.8(0.99)$ & $6.1^{* * *}(1.49)$ \\
\hline$n$ & 3,238 & 2,752 & 20,038 & 17,422 & 3,796 & 3,186 \\
\hline Sulfonylurea & $5.5(1.20)$ & $1.0^{* * *}(0.16)$ & $5.3(1.43)$ & $2.2^{* * *}(0.46)$ & $6.5(2.00)$ & $4.8(0.92)$ \\
\hline$n$ & 1,967 & 1,041 & 16,095 & 6,555 & 2,948 & 875 \\
\hline Non-sulfonylurea & $8.8(3.15)$ & $5.8(1.43)$ & $9.9(3.29)$ & $6.6^{* * *}(1.72)$ & $11.3(4.08)$ & $8.5^{*}(2.33)$ \\
\hline$n$ & 2,380 & 2,579 & 12,941 & 18,579 & 3,791 & 4,813 \\
\hline \multicolumn{7}{|c|}{ Major hypoglycemia, \% patients with at least one event (event/person-year) } \\
\hline Entire cohort & $1.2(0.25)$ & $0.0^{* * *}(0.00)$ & $1.1(0.20)$ & $0.0^{* * *}(0.01)$ & $1.6(0.35)$ & $0.1^{* * *}(0.03)$ \\
\hline$n$ & 4,347 & 3,620 & 29,036 & 25,134 & 6,739 & 5,688 \\
\hline Insulin-experienced & $4.2(0.89)$ & $0^{* * *}(0)$ & $2.4(0.45)$ & $0.1^{* * *}(0.01)$ & $2.7(0.60)$ & $0.2^{* * *}(0.06)$ \\
\hline$n$ & 1,109 & 868 & 8,998 & 7,712 & 2,943 & 2,502 \\
\hline Insulin-naïve & $0.2(0.03)$ & $0.0(0.01)$ & $0.5(0.08)$ & $0.0^{* * *}(0.00)$ & $0.8(0.15)$ & $0^{* * *}(0)$ \\
\hline$n$ & 3,238 & 2,752 & 20,038 & 17,422 & 3,796 & 3,186 \\
\hline \multicolumn{7}{|c|}{ Nocturnal hypoglycemia, \% patients with at least one event (event/person-year) } \\
\hline Entire cohort & $3.2(0.63)$ & $1.2^{* * *}(0.20)$ & $3.1(0.65)$ & $1.5^{* * *}(0.29)$ & $3.6(0.93)$ & $2.6^{* * *}(0.52)$ \\
\hline$n$ & 4,347 & 3,620 & 29,036 & 25,134 & 6,739 & 5,688 \\
\hline Insulin-experienced & $8.0(1.78)$ & $3.3^{* * *}(0.51)$ & $6.6(1.51)$ & $2.5^{* * *}(0.49)$ & $6.6(1.72)$ & $3.8^{* * *}(0.76)$ \\
\hline$n$ & 1,109 & 868 & 8,998 & 7,712 & 2,943 & 2,502 \\
\hline Insulin-naïve & $1.5(0.24)$ & $0.5^{* * *}(0.10)$ & $1.5(0.27)$ & $1.1^{* * *}(0.20)$ & $1.3(0.32)$ & $1.6(0.33)$ \\
\hline$n$ & 3,238 & 2,752 & 20,038 & 17,422 & 3,796 & 3,186 \\
\hline \multicolumn{7}{|l|}{ Body weight (SD), kg } \\
\hline Entire cohort & $70.8(13.5)$ & $71.1^{* * *}(13.0)$ & $72.3(13.6)$ & $72.5^{* * *}(13.0)$ & $69.5(13.4)$ & $70.1^{* * *}(12.9)$ \\
\hline$n$ & 3,182 & & 21,757 & & 4,873 & \\
\hline Insulin-experienced & $72.9(15.5)$ & $73.2^{*}(15.1)$ & $75.8(15.0)$ & $75.9^{*}(14.5)$ & $72.0(14.3)$ & $72.3^{* * *}(14.0)$ \\
\hline$n$ & 747 & & 6,751 & & 2,136 & \\
\hline
\end{tabular}


Table 3 continued

\begin{tabular}{|c|c|c|c|c|c|c|}
\hline \multirow[t]{2}{*}{ Measurement } & \multicolumn{2}{|l|}{$\leq 40$ years } & \multicolumn{2}{|c|}{$>40-65$ years } & \multicolumn{2}{|l|}{$>65$ years } \\
\hline & Baseline & 24 weeks & Baseline & 24 weeks & Baseline & 24 weeks \\
\hline Insulin-naïve & $70.2(12.8)$ & $70.4^{* *}(12.3)$ & $70.7(12.6)$ & $70.9^{* * *}(12.0)$ & $67.5(12.3)$ & $68.5^{* * *}(11.7)$ \\
\hline$n$ & 2,435 & & 15,006 & & 2,737 & \\
\hline
\end{tabular}

Due to the non-interventional nature of this study, not all baseline data were recorded and some patients were lost to follow-up ${ }^{* * *} p<0.001$ vs. baseline

${ }^{* *} p<0.01$ vs. baseline

${ }^{*} p<0.05$ vs. baseline

\section{SADRS}

Of the 40,122 people receiving biphasic insulin aspart 30 ( \pm OGLDs), there were 16 reports of SADRs: 5 in the $\leq 40$ years age-group, including 3 hypoglycemia episodes, 1 report of diabetic ketoacidosis, and 1 episode of hypoglycemia unawareness; 5 in the $>40-65$ years age-group, including 3 hypoglycemia episodes, 1 report of hyperglycemia, and 1 episode of hypoglycemia unawareness; and 6 in the $>65$ years age-group, including 5 hypoglycemia episodes and 1 episode of hypoglycemia unawareness. Ten of these were probably related to biphasic insulin aspart 30 ( \pm OGLDs) treatment (with good reasons and sufficient documentation to assume a causal relationship) and 6 were possibly related (a causal relationship was conceivable and could not be dismissed).

\section{Body Weight}

There was a modest, but statistically significant $(p<0.001)$, weight gain $(0.2-0.7 \mathrm{~kg})$ after 24 weeks in all age-groups (Table 3 ). Weight gain with biphasic insulin aspart 30 treatment appeared to be similar in both insulin-experienced and insulinnaïve patients (Table 3).

\section{Effectiveness Measures}

\section{Glycemic Measures}

Mean baseline $\mathrm{HbA}_{1 \mathrm{c}}$ levels were high in all agegroups (ranging from $9.4 \%$ to $9.6 \%$ ), and after
24 weeks of treatment with biphasic insulin aspart 30, all age-groups showed statistically significant improvements $(p<0.001$; Table 4$)$. Likewise, $\mathrm{HbA}_{1 \mathrm{c}}$ levels were statistically significantly reduced in all age-groups after 24 weeks in insulin-experienced and insulinnaïve patients $(p<0.001$; Table 4$)$. In all agegroups, improvements in $\mathrm{HbA}_{1 \mathrm{c}}$ values appeared to be greater in insulin-naïve patients than in insulin-experienced patients (Table 4). The length of time since diagnosis of diabetes in years did not appear to affect the magnitude of reduction in $\mathrm{HbA}_{1 \mathrm{c}}$ levels after 24 weeks of biphasic insulin aspart 30 treatment (results not shown).

Mean baseline FPG was high in all agegroups (ranging from 10.5 to $11.1 \mathrm{mmol} / \mathrm{l}$ ), and there were significant improvements in all age-groups after 24 weeks' treatment with biphasic insulin aspart 30 (Table 4). Improvements in FPG appeared to be slightly greater in the insulin-naïve group than the insulin-experienced group after 24 weeks in all age-groups (Table 4). Likewise, baseline PPG was high in all age-groups, and after 24 weeks' treatment with biphasic insulin aspart 30, statistically significantly improvements were observed in all age-groups (Table 4). Improvements after 24 weeks appeared to be greater in the insulin-naïve group in all agegroups (Table 4). Improvements in FPG and PPG levels at 24 weeks appeared to be greatest in the 


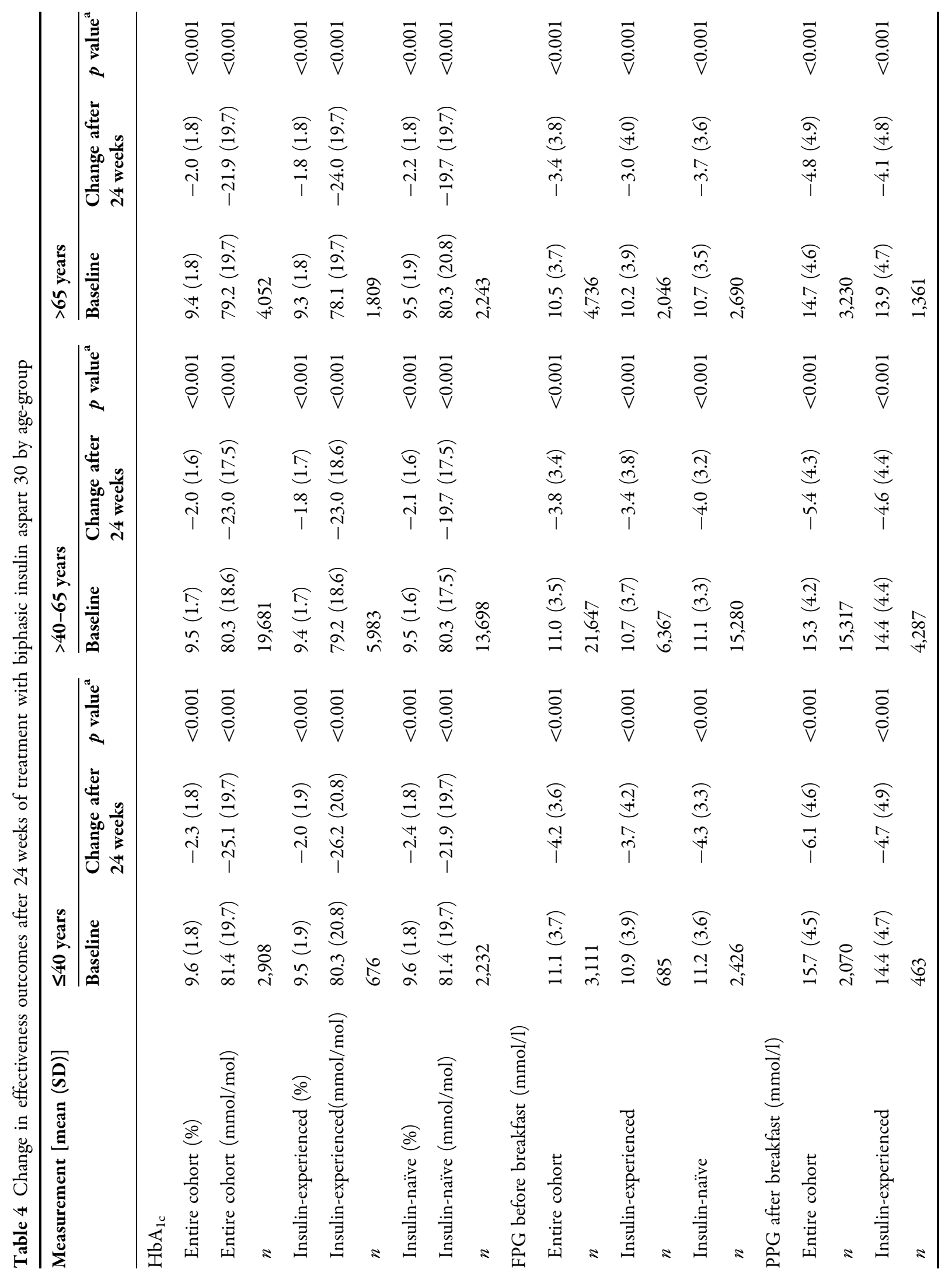




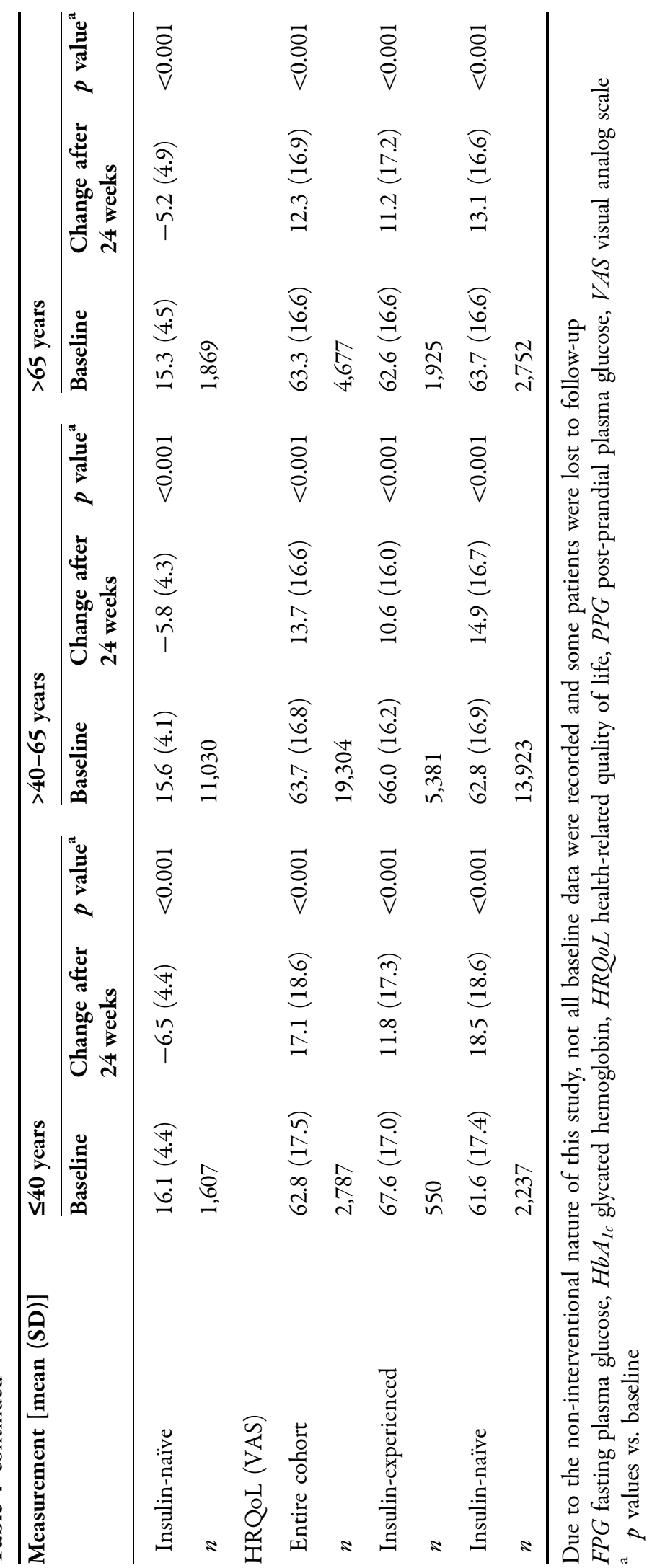


$\leq 40$ years age-group and least in $>65$ years agegroup.

\section{HRQoL}

There was statistically significant $(p<0.001)$ improvement in VAS scores after 24 weeks in all age-groups (Table 4). Statistically significant increases in VAS scores were observed for both insulin-experienced and insulin-naïve patients in all age-groups $(p<0.001$; Table 4$)$.

\section{DISCUSSION}

This sub-analysis of age-specific data from the $A_{1}$ chieve study showed that starting, or switching to, insulin therapy with biphasic insulin aspart 30 ( \pm OGLDs) under routine clinical practice led to significant improvements in blood glucose levels (as measured by $\mathrm{HbA}_{1 \mathrm{c}}$, FPG and PPG) across 3 age-groups. These results are consistent with previous studies that showed in people with type 2 diabetes that starting insulin therapy with once- or twice-daily biphasic insulin aspart 30 led to effective glycemic control [18, 19]. Another study also showed that biphasic insulin aspart 30 may lead to improved PPG control compared with other insulin therapies [20].

Importantly, the significant improvement in glycemic control was achieved with a significant reduction in the proportion of participants in the entire cohort reporting major hypoglycemia during the 24 weeks of treatment with biphasic insulin aspart 30 ( \pm OGLDs) relative to baseline. The results appeared to be generally consistent across the 3 age-groups assessed and between insulinnaïve and insulin-experienced patients. Some variation in the specific pattern of results was observed and these will be discussed.

The reduction in the incidence of hypoglycemia observed for the entire cohort in all age-groups may potentially be explained by the reduced sulfonylurea use after 24 weeks, but may also be due to optimization of the biphasic insulin aspart 30 dosage during the 24 weeks of the study. Others have reported a lower proportion of people experiencing hypoglycemia in patients receiving biphasic insulin aspart 30 who have optimized their insulin dosage [28]. Furthermore, the proportion of participants reporting hypoglycemia was significantly reduced in all age-groups switching from other insulin regimens to biphasic insulin aspart 30 treatment, as would be expected from the significant reductions in the whole $A_{1}$ chieve study population [24]. This result may also have been driven by the high baseline values in all age-groups of insulin-experienced participants. However, while the proportion was also significantly reduced in insulin-naïve patients aged $\leq 40$ years, it was significantly increased in the $>65$ years age-group. Elderly individuals with diabetes are at higher risk of hypoglycemia than younger people due to risk factors such as co-morbidities, polypharmacy, and cognitive impairment [29]—this may explain the age differences in hypoglycemia rates. Reported major hypoglycemia episodes were rare during treatment with biphasic insulin aspart 30, as seen in other noninterventional studies [30], with statistically significant improvements from baseline in all age-groups. Furthermore, there was a low incidence of SADRs in all three age-groups, with no suggestion that these were more likely in one group over another. While it is not surprising that patients already receiving insulin therapy at baseline had what appeared to be higher rates of overall hypoglycemia, major hypoglycemia and nocturnal hypoglycemia than those who were insulinnaïve pre-study, it is unclear why the 
proportion of patients reporting nocturnal hypoglycemia at baseline appeared to be much higher among insulin-experienced patients in the $\leq 40$ years age-group.

Changes to body weight with biphasic insulin aspart 30 therapy were modest (generally $<1 \mathrm{~kg}$ ); weight gain was greatest in the $>65$ years age-group, but the differences between age-groups were not large and may not have any clinical relevance. As expected, insulin-experienced patients appeared to weigh more at baseline than insulin-naïve participants in all age-groups, but there was no clear difference in weight gain between the 2 groups after 24 weeks in any age-group. Other studies have reported weight gain with use of biphasic insulin aspart 30 [12, 19, 31]; for example, in an open-label, controlled trial of patients with type 2 diabetes and suboptimal $\mathrm{HbA}_{1 \mathrm{c}}$, 1-year treatment with biphasic insulin aspart 30 plus metformin and sulfonylurea was associated with a mean weight gain of $4.7 \mathrm{~kg}$ [32].

Reductions in FPG and PPG appeared to be greater in insulin-naïve patients than in insulinexperienced patients, possibly because baseline levels were higher among insulin-naïve patients. This baseline finding is consistent with baseline results in the IMPROVE and Physicians' Routine Evaluation of Safety and Efficacy of NovoMix 30 Therapy non-interventional studies of people with type 2 diabetes starting or switching to biphasic insulin aspart as part of routine clinical care $[15,16]$. As would be expected following these significant reductions in FPG and PPG after 24 weeks, clinically meaningful improvements in $\mathrm{HbA}_{1 \mathrm{c}}$ values were seen in both the insulin-naïve and insulin-experienced participants in all age-groups, and the improvements seemed to be slightly larger for the insulin-naïve participants. However, this was not caused by higher baseline $\mathrm{HbA}_{1 \mathrm{c}}$ values among insulin-naïve patients, as both patient groups appeared to have similar baseline $\mathrm{HbA}_{1 \mathrm{c}}$ values. That clinically meaningful improvements in $\mathrm{HbA}_{1 \mathrm{c}}$ values were seen in the $>65$ years age-group is encouraging given the additional challenges elderly patients face in managing their diabetes, such as cognitive impairment, co-morbidities and polypharmacy, among other issues.

Although participation in the study alone could improve perceived HRQoL regardless of treatment, it is encouraging that starting or switching to biphasic insulin aspart 30 significantly improved HRQoL in all agegroups, as reported previously for the total $\mathrm{A}_{1}$ chieve population [33].

There are limitations to the current study that are inherent in the study design of noninterventional studies. These include the lack of randomization and the absence of a control arm, and assessment of some parameters (e.g., hypoglycemia events) being based on participant recall and self-reported information. In addition, this study did not control for concomitant medication and dietary intake. However, non-interventional studies have the advantages of enabling a larger body of data to be analyzed and a greater variety of important disease and therapy-related questions to be explored than can be assessed in an RCT.

In summary, this sub-analysis of data from the $A_{1}$ chieve study suggests that in people with type 2 diabetes with poor glycemic control, starting or switching to biphasic insulin aspart 30 ( \pm OGLDs) provides valuable improvements in glycemic control. Importantly, the effectiveness and tolerability of biphasic insulin aspart 30 are consistent across different age-groups. This is particularly reassuring in the elderly population who may face more challenges to achieving glycemic control compared with younger patients. Furthermore, hypoglycemia episodes reported in insulin- 
naïve patients aged $>65$ years suggest that there should be a greater focus on education when elderly people are initiating insulin therapy.

\section{ACKNOWLEDGMENTS}

The $A_{1}$ chieve study and this manuscript were funded by Novo Nordisk A/S (Bagsvaerd, Denmark). Editorial assistance on this manuscript was provided by Nicole Meinel and Daniella Otway of ESP Bioscience (Crowthorne, UK), funded by Novo Nordisk A/S. Ole Molskov Bech is the guarantor for this article, and takes responsibility for the integrity of the work as a whole.

Conflict of interest. Mohammad Ebrahim Khamseh participated in a national multicenter clinical trial sponsored by Novo Nordisk. Jihad Haddad has acted as a speaker for Novo Nordisk, Novartis, MSD, Merck Serono, and Astra Zeneca, and as an advisory board member for Novo Nordisk and Merck Serono. Wenying Yang declares no conflict of interest. Alexey Zilov is working as a lecturer for Abbot, Astra Zeneca/BMS, Bayer, Berlin-Hemi, Novartis, Novo Nordisk, and Sanofi, and participated in clinical trials sponsored by Lilly, Novartis, Novo Nordisk, and Sanofi. Ole Molskov Bech is an employee of Novo Nordisk. Mohammad Imtiaz Hasan is a member of the Global $\mathrm{A}_{1}$ chieve Advisory Board funded by Novo Nordisk, and has participated in clinical trials conducted by Roche and Novartis.

Compliance with ethics guidelines. Insulin analogs were used in the study in accordance with the label approved by the regulatory authority (all manufactured by Novo Nordisk A/S, Bagsvaerd, Denmark), and all local requirements for Health Authorities or Ethics
Committee approvals were obtained, if applicable. In every country, participants signed informed consent forms and were free to withdraw from the study at any time. The study was conducted in accordance with the Declaration of Helsinki of 1964, as revised in 2008 [25] and guidelines for good pharmacoepidemiology practice [26].

Open Access. This article is distributed under the terms of the Creative Commons Attribution Noncommercial License which permits any noncommercial use, distribution, and reproduction in any medium, provided the original author(s) and the source are credited.

\section{REFERENCES}

1. International Diabetes Federation. IDF Diabetes Atlas. 4th ed. International Diabetes Federation, Belgium; 2009.

2. Cowie CC, Rust KF, Ford ES, et al. Full accounting of diabetes and pre-diabetes in the US population in 1988-1994 and 2005-2006. Diabetes Care. 2009; $32: 287-94$.

3. Mooradian AD, McLaughlin S, Boyer CC, Winter J. Diabetes care for older adults. Diabetes Spectr. 1999;12:70-7.

4. Geddes J, Schopman JE, Zammitt NN, Frier BM. Prevalence of impaired awareness of hypoglycaemia in adults with type 1 diabetes. Diabet Med. 2008; 25:501-4.

5. Chan TY. Estimates on the incidence of antidiabetic drug-induced severe hypoglycaemia in Hong Kong. Pharmacoepidemiol Drug Saf. 1998;7:411-4.

6. Brown AF, Mangione CM, Saliba D, Sarkisian CA. Guidelines for improving the care of the older person with diabetes mellitus. J Am Geriatr Soc. 2003;51:S265-80.

7. Korytkowski M. When oral agents fail: practical barriers to starting insulin. Int J Obes Relat Metab Disord. 2005;26(Suppl. 3):S18-24.

8. Peyrot M, Rubin RR, Lauritzen T, et al. Resistance to insulin therapy among patients and providers: results of the cross-national Diabetes Attitudes, 
Wishes, and Needs (DAWN) study. Diabetes Care. 2005;28:2673-9.

9. Dornhorst A, Luddeke HJ, Sreenan S, et al. Insulin detemir improves glycaemic control without weight gain in insulin-naive patients with type 2 diabetes: subgroup analysis from the PREDICTIVE study. Int J Clin Pract. 2008;62:659-65.

10. Fajardo Montanana C, Hernandez Herrero C, Rivas Fernandez M. Less weight gain and hypoglycaemia with once-daily insulin detemir than NPH insulin in intensification of insulin therapy in overweight type 2 diabetes patients: the PREDICTIVE BMI clinical trial. Diabet Med. 2008;25:916-23.

11. Hermansen K, Davies M, Derezinski T, Martinez Ravn G, Clauson P, Home P. A 26-week, randomized, parallel, treat-to-target trial comparing insulin detemir with $\mathrm{NPH}$ insulin as add-on therapy to oral glucose-lowering drugs in insulin-naive people with type 2 diabetes. Diabetes Care. 2006;29:1269-74.

12. Liebl A, Prager R, Binz K, Kaiser M, Bergenstal R, Gallwitz B. Comparison of insulin analogue regimens in people with type 2 diabetes mellitus in the PREFER study: a randomized controlled trial. Diabetes Obes Metab. 2009;11:45-52.

13. Meneghini L, Mersebach H, Kumar S, Svendsen AL, Hermansen K. Comparison of 2 intensification regimens with rapid-acting insulin aspart in type 2 diabetes mellitus inadequately controlled by oncedaily insulin detemir and oral antidiabetes drugs: the step-wise randomized study. Endocr Pract. 2011;17:727-36.

14. Philis-Tsimikas A, Charpentier G, Clauson P, Ravn GM, Roberts VL, Thorsteinsson B. Comparison of once-daily insulin detemir with NPH insulin added to a regimen of oral antidiabetic drugs in poorly controlled type 2 diabetes. Clin Ther. 2006;28:1569-81.

15. Sharma S, Al-Mustafa M, Oh S, et al. Biphasic insulin aspart 30 treatment in patients with type 2 diabetes poorly controlled on prior diabetes treatment: results from the PRESENT study. Curr Med Res Opin. 2008;24:645-52.

16. Valensi P, Benroubi $M$, Borzi $V$, et al. The IMPROVE study-a multinational, observational study in type 2 diabetes: baseline characteristics from eight national cohorts. Int J Clin Pract. 2008;62:1809-19.

17. Warren ML, Conway MJ, Klaff LJ, Rosenstock J, Allen E. Postprandial versus preprandial dosing of biphasic insulin aspart in elderly type 2 diabetes patients. Diabetes Res Clin Pract. 2004; 66:23-9.
18. Garber AJ, Wahlen J, Wahl T, et al. Attainment of glycaemic goals in type 2 diabetes with once-, twice-, or thrice-daily dosing with biphasic insulin aspart 70/30 (the 1-2-3 study). Diabetes Obes Metab. 2006;8:58-66.

19. Raskin P, Allen E, Hollander $P$, et al. Initiating insulin therapy in type 2 diabetes: a comparison of biphasic and basal insulin analogs. Diabetes Care. 2005;28:260-5.

20. Hermansen K, Colombo M, Storgaard H, Ostergaard A, Kolendorf K, Madsbad S. Improved postprandial glycemic control with biphasic insulin aspart relative to biphasic insulin lispro and biphasic human insulin in patients with type 2 diabetes. Diabetes Care. 2002;25:883-8.

21. Strojek K, Bebakar WM, Khutsoane DT, et al. Oncedaily initiation with biphasic insulin aspart 30 versus insulin glargine in patients with type 2 diabetes inadequately controlled with oral drugs: an open-label, multinational RCT. Curr Med Res Opin. 2009;25:2887-94.

22. Boehm BO, Home PD, Behrend C, Kamp NM, Lindholm A. Premixed insulin aspart 30 vs. premixed human insulin 30/70 twice daily: a randomized trial in type 1 and type 2 diabetic patients. Diabet Med. 2002;19:393-9.

23. Boehm BO, Vaz JA, Brondsted L, Home PD. Longterm efficacy and safety of biphasic insulin aspart in patients with type 2 diabetes. Eur J Intern Med. 2004;15:496-502.

24. Home $P$, Naggar NE, Khamseh $M$, et al. An observational non-interventional study of people with diabetes beginning or changed to insulin analogue therapy in non-Western countries: the $\mathrm{A}_{1}$ chieve study. Diabetes Res Clin Pract. 2011;94:352-63.

25. World Medical Association. Declaration of Helsinki-ethical principles for medical research involving human subjects 2008. http://www. riip-influenza.org/wp-content/uploads/2011/08/ Helsinki-2008-EN.pdf. Accessed Nov 8, 2011.

26. International Society for Pharmacoepidemiology. Guidelines for good pharmacoepidemiology practices (GPP). Revision 2, Apr 2007. http://www. pharmacoepi.org/resources/guidelines_08027.cfm. Accessed Jul 2, 2013.

27. The EuroQol group. EuroQol-a new facility for the measurement of health-related quality of life. EuroQol Group Health Policy. 1990;16:199-208.

28. Trippe BS, Shepherd MD, Coulter FC, et al. Efficacy and safety of biphasic insulin aspart 70/30 in type 2 diabetes patients of different race or ethnicity 
(INITIATEplus trial). Curr Med Res Opin. 2012;28:1203-11.

29. Ligthelm RJ, Kaiser M, Vora J, Yale JF. Insulin use in elderly adults: risk of hypoglycemia and strategies for care. J Am Geriatr Soc. 2012;60:1564-70.

30. Valensi P. Biphasic insulin aspart 30/70 (BIAsp 30) in the treatment of type 1 and type 2 diabetes. Diabetes, Metab Syndr Obes Targets Ther. 2009;2:61-71.

31. Qayyum R, Bolen S, Maruthur N, et al. Systematic review: comparative effectiveness and safety of premixed insulin analogues in type 2 diabetes. Ann Intern Med. 2008;149:549-59.

32. Holman RR, Thorne KI, Farmer AJ, et al. Addition of biphasic, prandial, or basal insulin to oral therapy in type 2 diabetes. N Engl J Med. 2007;357:1716-30.

33. Shah S, Zilov A, Malek R, Soewondo P, Bech O, Litwak L. Improvements in quality of life associated with insulin analogue therapies in people with type 2 diabetes: results from the $\mathrm{A}_{1}$ chieve observational study. Diabetes Res Clin Pract. 2011;94:364-70. 